\title{
APLICAÇÃO DO HERBICIDA DICLOFOP NA CULTURA DA SOJA PARA CONTROLE DE PAPUÃ, Brachiaria plantaginea (Linck) Hitch.
}

N.G. FLECK *

\section{RESUMO}

Durante o ano agrícola de $1977 / 78$ foi conduzida uma pesquisa a campo na região da Depressão Central do Rio Grande do Sul, com o objetivo de estabelecer a dose e a época de aplicação do herbicida diclofop que proporcionassem controle mais eficiente do Papua e que oferecessem maior seletividade à cultura. Os tratamentos constaram de combinações das doses de 720, 1080 e 1440 $\mathrm{g} /$ ha de diclofop, e aplicações em pré-plantio incorporadas ao solo (PPI), pré-emergência (PRE), pós-emergência quando as plântulas de papuã se apresentavam com duas folhas (POS-2) e outra na ocasião em que se encontravam no estádio de quatro folhas (POS-4), as quais foram comparadas às testemunhas com papuã durante o ciclo da soja (TCP) e sem papuã (TSP). Os efeitos dos tratamentos foram estimados através de avaliações visuais de controle e pelo rendimento de grãos de soja.

Todos os tratamentos com diclofop proporcionaram rendimentos estatisticamente equivalentes, os quais não se diferenciaram do controle sem papuã, embora tivessem apresentado rendimentos significativamente superiores ao daquele com papuã..

Resultados das avaliações visuais, interpretados conjuntamente, evidenciaram que todas as combinações de doses e épocas de aplicação do diclofop controlaram eficientemente o papuã. As percentagens do controle alcançado, em relação às testemunhas, variaram de 68 a 99\%, dependendo do tratamento e da época da avaliação. Contudo, as aplicações em POS-2 nas doses
Professor Adjunto - Depto. de Fitotecnia da Faculdade de Agronomia da UFRGS - Porto Alegre-RS - 90.000.Bolsista do CNPq.

Trabalho realizado com recurs os provenientes do CN Pq, da FAPERGS, da UFRGS e da Hoechst do Brasil.

Trabalho parcialmente apresentado no XII Seminário Brasileiro de Herbicidas e Ervas Daninhas, Fortaleza, CE, 1978.

Recebido para publicação em 16.01.79.

de 1080 e $1440 \mathrm{~g} / \mathrm{ha}$ e em POS-4 na dose de $1080 \mathrm{~g} / \mathrm{ha}$ demonstraram maior eficiência em controlar papuã do que aquelas em PPI e em PRE à $720 \mathrm{~g} / \mathrm{ha}$.

UNITERMOS: diclofop, soja, papuã, Brachiaria plantaginea.

\section{SUM MARY}

APPLICATION OF THE HERBICIDE DICLOFOP IN SOYBEAN FOR CONTROL OF Brachiaria plantaginea (Linck) Hitch.

During the $1977 / 78$ soybean season a field experiment was conducted in the Central Depression Region of Rio Grande do Sul, in order to evaluate the application rate and time for the herbicide diclofop to control most efficiently Brachiaria plantaginea and also offer the greatest selectivity to the crop.

The treatments tested were combinations of diclofop at 720,1080 , and $1440 \mathrm{~g} / \mathrm{ha}$, with at pre-plant incorporated applications (PPI), preemergenge (PRE), post-emergence when weed seedlings presented two leaves (POS-2) or at four-leaves stage (POS-4); these were compared to the control plots with Brachiaria during all soybean season (TCP) and without the weed (TSP). The effects of the treatments were estimated through visual evaluations of weed control and also by soybean seed yields.

There were no significant differences among the diclofop treatments for soybean seed yields, which also were not different from the control 
TSP, although yields produced in all these treatments were significantly greater than that of TCP.

Combined results of all visual evaluations showed that all diclofop treatments controlled efficiently the weed. In relation to the checks, percentages of control obtained, varied from 68 to $99 \%$, depending on the treatment and evaluation. However, applications of diclofop in POS- 2 when rates of 1080 and $1440 \mathrm{~g} /$ ha were used, and in POS-4 at $1080 \mathrm{~g} / \mathrm{ha}$, demonstrated greater efficiency in controlling Brachiaria than those in PPI and PRE at $720 \mathrm{~g} / \mathrm{ha}$. KEYWORDS: diclofop, soybean, Brachiaria
plantaginea.

\section{INT RODUÇÃO}

Diversos herbicidas estão disponiveis para controlar plantas daninhas gramineas anuais em soja; entretanto, praticamente todos são produtos cuja aplicação está restrita ao solo, seja em pré-plantio ou em pré-emergência da cultura. A viabilidade da aplicação de um graminicida em pós-emergência da soja permitiria uma inspeção prévia do grau de infestação das plantas daninhas, possibilitando deste modo uma avaliação da economicidade do uso do herbicida e a escolha adequada da dose a utilizar segundo a infestação e o estádio de desenvolvimento das mesmas.

Ramos (6) considera o controle das plantas daninhas na cultura da soja, através de produtos seletivos de aplicação em pós-emergência uma tecnologia promissora, especialmente na utilização de semeadura direta, e acrescenta que o controle do papuã, Brachiaria plantaginea, geralmente constitui um sério entrave para a utilização deste sistema.

O diclofop, segundo Chow (2), é úm herbicida de pós-emergência, altamente seletivo, que foi avaliado na Europa e nos Estados Unidos em diversas culturas. Em tratamentos testados em pós-emergência, Ramos (6) obteve resultados que indicaram excelente efeito do diclofop sobre o papuã, dependendo da dose e da época de aplicação.
Wu \& Santelmann (8) e Andersen (1) confirmaram que o diclofop tem demonstrado considerável potencial para controlar plantas daninhas gramíneas anuais em várias culturas gramíneas e dicotiledôneas, e Todd \& Stobbe (7) referiram que controle seletivo com este herbicida também tem sido obtido por tratamentos incorporados ao solo.

Hoechst (4) afirma que todas as espécies gramineas suscetiveis às aplicações de diclofop em pós-emergência também são controladas com tratamentos em pré-emergência. Entretanto, Hoechst (5) sugere que os melhores resultados são obtidos quando diclofop é aplicado no estádio inicial de desenvolvimento das gramíneas.

Os objetivos desta pesquisa foram os de avaliar a eficiência do herbicida diclofop no controle de papuã, de estabelecer a dose e a época de aplicação que propiciassem controle mais eficiente desta e que oferecessem maior seletividade para a cultura da soja, bem como comparar aplicações realizadas sobre o solo e sobre a folhagem.

\section{MATERIAL E MÉT ODOS}

A pesquisa foi conduzida a campo durante o ano agrícola de $1977 / 78$ na Estação Experimental Agronômica (EEA) da Universidade Federal do Rio Grande do Sul (UFRGS), que se localiza no município de Guaíba, região fisiográfica da Depressão Central do Estado, em solo pertencente à unidade de mapeamento Arroio dos Ratos, classificado como de textura arenosa, contendo $10 \%$ de argila e $1 \%$ de matéria orgânica no horizonte A. A correção e adubação da área foram efetuadas conforme recomendações provenientes da análise executada pelo Laboratório de Análises de Solo da Faculdade de Agronomia da UFRGS.

A semeadura da soja, cultivar Planalto, foi realizada com semeadeira manual do tipo "Planet" no dia 27 de outubro. As sementes de soja, previa- 
mente inoculadas, e semeadas em fileiras espaçadas de $50 \mathrm{~cm}$, propiciaram uma densidade de 15 plantas por metro linear ou uma população média de 300.000 plantas por hectare. A colheita da soja ocorreu a 4 de abril, cerca de 150 dias após sua emergência. Colheram-se as duas fileiras de soja situadas no centro da parcela, em área útil de $5 \mathrm{~m}^{2}$, tendo então o material sido trilhado e pesado para obtenção do rendimento de grãos.

Os tratamentos, arranjados no delineamento experimental de blocos ao acaso, foram repetidos cinco vezes. As unidades experimentais apresentavam dimensões de $2 \times 5 \mathrm{~m}\left(10 \mathrm{~m}^{2}\right)$, e estavam constituídas por quatro fileiras de soja de $5 \mathrm{~m}$ de comprimento.

Os tratamentos testados no experimento constaram de combinações das doses de 720, 1080 e 1440 g/ha de diclofop, ácido 2-[4-(2;4diclor ofenoxi)fe noxi] propanóico, com aplicações em pré-plan tio incorporadas ao solo (PPI), pré-emergência (PRE), pós-emergência quando as plântulas de papuã se apresentavam com duas folhas (POS-2) e pós-emergência na ocasião em que se encontravam no estádio de quatro folhas (POS-4), os quais foram comparados às testemunhas com papuã (TCP) durante o ciclo da soja e sem papuã (TSP). A testemunha sem papuã recebeu duas capinas manuais, respectivamente aos 20 e aos 35 dias após a emergência da soja.

Os tratamentos em PPI foram aplicados 3 dias antes da semeadura da soja, ocasião em que a camada superficial do solo se apresentava com deficiência de umidade. Imediatamente após as pulverizações, seguiu-se a incorporação do produto ao solo a uma profundidade entre 3 e $5 \mathrm{~cm}$, para o que foi utilizado um microtrator equipado com enxada rotativa.

As aplicações dos tratamentos em PRE foram realizadas no mesmo dia, em seguida à semeadura da soja. com adequado teor de umidade, exceto superficialmente. Constatou-se a ocorrência de chuva no quarto dia após as aplicações destes tratamentos.

Os tratamentos em POS-2 foram aplicados 2 dias após a emergência da soja, cujas plântulas se apresentavam com duas folhas simples e as de papuã no estádio de uma a duas folhas. Realizaram-se as pulverizações dos tratamentos em POS-4 9 dias após a emergência das plântulas de soja, que se encontravam com a primeira folha trifoliolada expandida, enquanto que as plântulas de papuã se apresentavam no estádio de duas a quatro folhas.

Os tratamentos com diclofop foram aplicados por meio de um pulverizador costal com vazão impelida por $\mathrm{CO}_{2}$, utilizando-se bicos em leque 8004 , pressão constante de $2,8 \mathrm{~kg} / \mathrm{cm}^{\prime}$ e volume de solução de 315 1/ha. Não foi adicionado qualquer adjuvante às soluções de herbicida.

Os efeitos dos tratamentos foram avaliados através dos rendimentos de grãos de soja obtidos, e por meio de três avaliações visuais de controle, realizadas respectivamente aos 20 e aos 35 dias após aplicação dos últimos tratamentos com herbicida (ou 30 e 45 dias após a emergência da soja), enquantc que a última avaliação ocorreu por oca sido da colheita da cultura (150 dias após a emergência).

Para estabelecer os graus de controle alcançados, as avaliações visuais foram baseadas em escala percentual de zero a cem, onde zero representou nenhum controle de papuã e cem significou controle total da gramínea. Nãc foi realizada contagem da população $d E$ papuã existente sobre a área experimental.

Os dados coletados foram submetidos à análise da variância e as médias dos tratamentos foram comparadas aplicando-se o teste de Duncan ao nive] de $5 \%$ de probabilidade. 


\section{RESULTADOS E DISCUSSÃO}

Os dados resultantes dos efeitos dos tratamentos para rendimento de grãos de soja são encontrados no quadro 1. Com relação a este parâmetro, constatou-se que todos os tratamentos com o herbicida diclofop, nas várias combinações de doses e de épocas de aplicação, proporcionaram rendimentos de grãos que foram estatisticamente equivalentes, os quais também não diferiram do tratamento testemunha capinado. Contudo, o rendimento da soja obtido na testemunha onde não foi efe- tuado controle ao papuã foi significativamente inferior aos rendimentos de quaisquer dos tratamentos onde houve controle da espécie infestante.

Os resultados obtidos por Ramos (6) também indicaram que, quando diclofop foi aplicado no estádio em que o papuã apresentava três folhas, não houve diferença entre doses, quanto ao rendimento da soja, embora a dose de 1620 $\mathrm{g} /$ ha tives se proporcionado melhor controle da erva daninha.

Atribuiu-se a não diferenciação estatística entre os tratamentos herbicidas testados a duas causas principais:

Quadro 1. Efeitos de doses e de épocas de aplicação do herbicida diclofop na cultura da soja, EEA, Guaíba, RS, $1977 / 78$.

\begin{tabular}{|c|c|c|c|c|c|}
\hline \multirow[b]{2}{*}{ Tratamentos } & \multirow{2}{*}{$\begin{array}{l}\text { Rendimen- } \\
\text { to de grãos } \\
\text { de soja em } \\
\mathrm{kg} / \mathrm{ha}\end{array}$} & \multicolumn{4}{|c|}{ Avaliação visuais de controle do papuã 1} \\
\hline & & 30 dias & 45 dias & 150 dias & Médias \\
\hline Testemunha sem papuã & $2160 \mathrm{a}$ & $100 \mathrm{a}$ & $100 \mathrm{a}$ & 94 a & 98,0 \\
\hline Pós-emergência, 2 folhas, $1440 \mathrm{~g} / \mathrm{ha}$ & 1930 a & $98 \mathrm{ab}$ & $98 \mathrm{ab}$ & 98 a & 98,0 \\
\hline Pós-emergência, 2 folhas, $1080 \mathrm{~g} / \mathrm{ha}$ & $2050 \mathrm{a}$ & $96 \mathrm{ab}$ & $99 \mathrm{a}$ & 98 a & 97,7 \\
\hline Pós-emergência, 4 folhas, $1080 \mathrm{~g} / \mathrm{ha}$ & 2060 a & $96 \mathrm{ab}$ & 99 a & $96 \mathrm{a}$ & 97,0 \\
\hline Pré-plantio, incorporado, $1440 \mathrm{~g} / \mathrm{ha}$ & 2070 a & $94 \mathrm{ab}$ & $92 \mathrm{abc}$ & $90 \mathrm{ab}$ & 92,0 \\
\hline Pós-emergência, 4 folhas, $1440 \mathrm{~g} / \mathrm{ha}$ & $1880 \mathrm{a}$ & $89 a b c$ & $93 \mathrm{abc}$ & $92 \mathrm{ab}$ & 91,3 \\
\hline Pós-emergência, 4 folhas, $720 \mathrm{~g} / \mathrm{ha}$ & $2160 \mathrm{a}$ & $90 \mathrm{abc}$ & $91 \mathrm{abc}$ & $90 \mathrm{ab}$ & 90,3 \\
\hline Pré-plantio, incorporado, $1080 \mathrm{~g} / \mathrm{ha}$ & $2060 \mathrm{a}$ & $89 \mathrm{abc}$ & 85 bc & $92 \mathrm{ab}$ & 88,8 \\
\hline Pós-emergência, 2 folhas, $720 \mathrm{~g} / \mathrm{ha}$ & 2050 a & $88 \mathrm{abc}$ & $88 \mathrm{abc}$ & $90 a b$ & 88,7 \\
\hline Pré-emergência, $1440 \mathrm{~g} / \mathrm{ha}$ & 1990 a & $89 a b c$ & $93 \mathrm{abc}$ & $82 \mathrm{~b}$ & 88,0 \\
\hline Pré-emergência, $1080 \mathrm{~g} / \mathrm{ha}$ & 1910 a & $85 \mathrm{bc}$ & $82 \mathrm{c}$ & $88 \mathrm{ab}$ & 85,0 \\
\hline Pré-plantio, incorporado, $720 \mathrm{~g} / \mathrm{ha}$ & $1950 \mathrm{a}$ & $81 \mathrm{c}$ & $80 \mathrm{c}$ & $70 \mathrm{c}$ & 77,0 \\
\hline Pré-emergência, $720 \mathrm{~g} / \mathrm{ha}$ & 1940 a & $70 \quad d$ & 70 & $68 \mathrm{c}$ & 69,3 \\
\hline Testemunha com papuã & $1150 \mathrm{~b}$ & 0 & 0 & 0 & 0,0 \\
\hline Médias & 1955 & 83,4 & 83,6 & 82,0 & 83,0 \\
\hline $\mathrm{F}$ & 3,91 & 83,45 & 67,78 & 84,28 & -- \\
\hline C.V. $(\%)$ & 14,3 & 7,4 & 8,3 & 7,5 & -- \\
\hline
\end{tabular}

Médias seguidas por letras idênticas, não apresentam diferença estastística ao nível de $5 \%$ de probabilidade, de acordo com o teste de Duncan.

1 Determinações visuais de controle expressas como percentagem em comparação às testemunhas, $\mathrm{e}$ avaliadas em três ocasiōes em relação à emergência da soja. 
ao controle adequado do papuã que estes tratamentos atingiram, e à relativamente longa estiagem que acompanhou o ciclo da soja, ocasionando crescimento pouco vigoroso da espécie infestante. Comparando-se os rendimentos dos tratamentos TSP e TCP, verificouse que a competição ocasionada pela infestação de papuã durante o ciclo da soja, causou uma redução da ordem de $47 \%$ no rendimento de grãos da cultura.

$\mathrm{O}$ quadro 1 também contém as percentagens médias de controle ao papuã, resultantes das três avaliações visuais efetuadas. Interpretando-se conjuntamente os resultados obtidos, verificou-se que todos os tratamentos de diclofop nas diversas associações de doses e de épocas de aplicação, controlaram com significativa eficiência a erva daninha em consideração, quando com parados ao TCP. As percentagens do controle alcançado, em relação às teste munhas, variaram numa amplitude de 68 a 99\%, dependendo do tratamento considerado e da época em que a avaliação foi realizada.

As aplicações de diclofop, entretanto, em POS-2 nas doses de 1440 e de $1080 \mathrm{~g} / \mathrm{ha}$ e em POS-4 na dose de $1080 \mathrm{~g} / \mathrm{ha}$ demonstraram eficiências significativamente superiores em controlar papuã do que os tratamentos em PPI em PRE, ambos na dose de 720 $\mathrm{g} / \mathrm{ha}$; estes também apresentaram controles estatisticamente inferiores ao da TSP. Mesmo o tratamento em PRE na dose de $1080 \mathrm{~g} / \mathrm{ha}$, mostrou, nas duas avaliações iniciais, controle insuficiente de papuã quando comparado ao TSP. Já os demais tratamentos com herbicida tenderam a apresentar desempenho intermediário em relação aos grupos anteriormente referidos.

Foi constatado que, ao serem combinadas as pulverizações realizadas sobre a folhagem (POS-2 e POS-4), estas atingiram um grau de controle de papuã $10 \%$ superior ao conjunto de aplicações efetuadas sobre o solo (PPI e $\mathrm{PRE}$ ). Chow (2), igualmente obteve efei- to de diclofop sobre toda a planta, quer aplicado à folhagem ou às raízes, entretanto, a redução do crescimento das es pécies testadas foi maior quando o herbicida foi aplicado à parte aérea. Do mesmo modo, Friesen et al. (3), demonstraram que a fitotoxicidade do herbicida seguindo a aplicação ao solo foi marcadamente menor do que com aplicação foliar, e indicaram que o diclofop também foi mais tóxico às ervas em emergência via contato foliar do que radicular, concluindo que a exposição foliar é mais importante para a fitotoxicidade do herbicida do que a radicular.

Em relação às aplicações sobre o solo, obs ervou-se que a incorporação do produto (PPI) aumentou o controle de papuã em aproximadamente $5 \%$, quando comparado à simples pulverização do herbicida sobre a superfície (PRE). $\mathrm{Wu} \&$ Santelmann (8) indicaram que provavelmente seja necessária incorporação do produto ao solo para obtenção de adequada atividade pré-emergente. Estudos realizados por Friesen et al. (3) sugeriram a possibilidade de ocorrer inativação do herbicida em solo seco e/ ou volatilização sob condições de lavoura.

Quanto aos tratamentos sobre a folhagem, aplicações do herbicida em POS-2 demonstraram apenas pequeno incremento de controle ao papuã em relação aos aplicados quando as ervas se encontravam no estádio de quatro folhas. Também Friesen et al. (3) verificaram que a eficiência de controle de gramineas anuais foi um pouco maior quando se encontravam no estádio de duas a quatro folhas, embora o controle destas espécies no estádio de cinco folhas também fosse aceitável.

Nas condições em que foi realizado este experimento, foi constatado que a dose de $720 \mathrm{~g} / \mathrm{ha}$ de diclofop em aplicação ao solo não pareceu ser sufuciente para propiciar um grau adequado de controle ao papuã, especialmente quan do não foi incorporada ao solo. Já em aplicação à folhagem, a dose de 720 
g/ha demonstrou controle satisfatório de papuã, que talvez pudesse ser incrementado pela adição de um adjuvante à solução de pulverização. Foi demonstrado por Chow (2) que o controle de Avena fatua L. foi grandemente aumentado quando adicionado um adjuvante ao diclofop, sugerindo que ao usar um adjuvante eficiente poderia ser reduzida a dose e o custo da aplicação de diclofop em lavouras.

Também foi verificado que não houve necessidade de ser utilizada dose superior a $1080 \mathrm{~g} / \mathrm{ha}$ de diclofop, pelo menos até o estádio em que as plântulas de papuã apresentavam quatro folhas, para alcançar significativos incrementos de controle; além do que, niveis maiores de herbicida poderiam representar tratamentos não-econômicos.

Além de ter sido conseguido um controle eficiente às plântulas de papuã entre duas e quatro folhas com a utilização das doses menores em pulverização sobre a folhagem, este tipo de tratamento também apresenta as vantagens de propiciar controle préemergente de ervas daninhas gramíneas anuais e de não depender diretamente da umidade do solo para atuar. Chow (2) encontrou que diclofop aplicado ao solo a $1100 \mathrm{~g} / \mathrm{ha}$ controlou Setaria viridis (L.) Beauv. semeada 3 semanas após aplicação do herbicida, provavelmente como resultado de absorção radicular. E acrescenta ser esta uma vantagem adicio- nal deste herbicida que normalmente controla gramíneas anuais por aplicação foliar.

\section{LIT ERATURA CITADA}

L. Andersen, R. N. Response of monocotyledons to HOE 22870 and HOE 23408. Weed Science, 24(3): 266-269, 1976.

2. Chow, P. N. P. Selectivity and site of action in relation to field performance of diclofop. Weed Science, 26(4): 352-358, 1978.

3. Friesen, H.A.; O'Sullivan, P.A.; Vanden Born, W. H. HOE 23408, a new selective herbicide for wild oats and green foxtail in wheat and barley. Can. Plant. Science, $\mathbf{5 6}$ : 567-578, 1976.

4. Hoechst. Herbicide HOE-23408. Somerville, New Jersey, American Hoechst Corporation, Agricultural Chemicals Department. 7p., 1976.

5. Hoechst. Technical information: HOE 23408. Frankfurt, Alemanha, Hoechst Aktiengesellschaft. 10p., 1976.

6. Ramos, M. Comunicado técnico; efeito de doses e épocas de aplicação do produto HOE 23408 no controle do papuã (Brachiaria plantaginea), em tratamento de pósemergência, na cultura da soja. Ponta Grossa, Paraná, Empresa Brasileira de Pesquisa Agropecuária. 3p., 1976.

7. Todd, B. G. \& Stobbe, E. H. Selectivity of dichlofop methyl among wheat, barley, wild oat (Avena fatua) and green foxtail (Setaria viridis). Weed Science, 25(5): 382-385, 1977.

B. Wu, C.H. \& Santelmann, P.W. Phytotoxicity and soil activity of HOE 23408. Weed Science, 24(6): 601-604, 1976. 